This is an Accepted Manuscript of an article published by Taylor \& Francis in Journal of Constructivist Psychology on 9 March 2018, available

online: https://www.tandfonline.com/doi/10.1080/10720537.2018.1433087 


\title{
Self-knowledge and Depressive Symptoms in Late Adolescence: A Study Using the Repertory Grid Technique
}

\author{
Maria João Carapeto ${ }^{1,2}$, Guillem Feixas ${ }^{1,3}$
}

\footnotetext{
${ }^{1}$ Department of Clinical Psychology and Psychobiology (Section Personality, Assessment and Psychological Treatments), University of Barcelona, Barcelona, Spain.

${ }^{2}$ Department of Psychology, School of Social Sciences, University of Evora, Évora, Portugal.

${ }^{3}$ The Institute of Neurosciences, University of Barcelona, Barcelona, Spain.
}

Corresponding Author:

Guillem Feixas, $\mathrm{PhD}$

Department of Clinical Psychology and Psychobiology

University of Barcelona

Campus Mundet-Passeig Vall d'Hebron, 171

E08035 Barcelona (Spain)

Phone: +34933125100

Email address: gfeixas@ub.edu

\section{ACKNOWLEDGMENTS}

We acknowledge the partial support received from the "Secretariat" for Universities and Research, "Conselleria" of Economy and Knowledge, "Generalitat de Catalunya" (Government of Catalonia, Spain) for the funded recognition of our research group (ref. SGR2014-717). 


\title{
Self-knowledge and Depressive Symptoms in Late Adolescence: A Study Using the Repertory Grid Technique
}

\begin{abstract}
The goal of this study is to explore the relationship, suggested by recent developmental approaches, between several aspects of self-knowledge organization and depressive symptomatology in late adolescence, within the comprehensive framework of Kelly's personal construct psychology. The repertory grid technique was used to obtain six measures of self-knowledge organization: global differentiation, polarization, presence of conflicts, and discrepancies between Actual Self, Ideal Self and Others. Two inventories were used to create two samples of late adolescents according to their level of depressive symptoms. Results supported the expectations of greater global differentiation and ActualIdeal Self discrepancy (or lower self-esteem) for adolescents with depressive symptoms, as well as a higher likelihood of intrapersonal conflicts. However, discrepancies between Self (Actual or Ideal), identification with, and perceived adequacy of, Others, and Polarization showed no significant differences. Furthermore, the association of symptom severity with different grid measures was stronger for adolescents with depressive symptoms. Results and limitations of this study are discussed, and the potential of using personal construct theory and the repertory grid technique in studies of self-knowledge and psychological adjustment during adolescence is explored.
\end{abstract}

Keywords: self-knowledge organization, adolescent development, depression, repertory grid technique, implicative dilemmas. 
The growing rates of depression found throughout adolescence (e.g., Hankin, 2015; Kovacs \& Devlin, 1998) may be related to developmental changes in self-knowledge organization or structure (such as identity formation, self-concept differentiation, selfdiscrepancies, etc.). Given the contradictory or inconsistent results produced by research in the field, some authors have emphasized the need for a more comprehensive understanding of a range of concepts and measures of self-knowledge organization and the importance of ascertaining their meaning and their relations with psychological adaptation (e.g., Campbell, Assanand \& Paula, 2003; Pilarska \& Suchańska, 2015; Schwartz, Klimstra, Luyckx, Hale III $\&$ Meeus, 2012). Others defend the need for structural measures of self-knowledge based on self-descriptions by the participants, rather than on the standardized lists most often provided by researchers (e.g., Campbell et al., 2003; Zhang, Xin \& Lin, 2012).

In this context, this study proposes to explore the relationship between self-knowledge organization and depression in late adolescence using Kelly's (1955) Personal Construct Psychology (PCP) approach. Conceptually, PCP has proven to be fruitful in the understanding of personal change (e.g., Chiari, 2016; Kelly, 1955; Salmon, 1985) and psychological problems such as depression (Kelly, 1955; Neimeyer, 1984). In addition, the repertory grid technique (RGT), one of PCP's most widely recognized assessment instruments, allows the measurement of a range of aspects of self-knowledge organization found in adolescence literature (such as self-differentiation, self-discrepancies, identity formation and individuation, self-esteem, internalization of self-standards, and intrapersonal conflicts), combining nomothetic and idiographic approaches to data analysis. Before introducing the PCP approach in more detail, we begin with a brief review of developmental perspectives of self-knowledge organization and its relation to internalized symptoms.

\section{Developmental Approaches to Self-knowledge Organization and Internalized Symptoms} during Adolescence 
Recent refinements of classical theories (Fischer \& Bidell, 2006; Harter, 2012; Meeus, 2011) and new theoretical frameworks (e.g., developmental psychopathology; Cicchetti \& Toth, 2009) suggest that developmental gains in self-knowledge organization across adolescence allow a more complex view of self and others, and a more effective, flexible adaptation to sociocultural contexts. However, they also bring (at least transitory) liabilities (see Meeus, Iedema, Maassen \& Engels, 2005; Moretti \& Higgins, 1999; Noam, Paget, Valiant, Borst \& Bartok, 1994).

One example comes from the cognitive-developmental perspective (e.g., Damon \& Hart, 1988; Fischer \& Kennedy, 1997; Glick \& Zigler, 1985; Harter, 2012; Oosterwegel \& Oppenheimer, 1993), according to which adolescents become able to organize self-knowledge in abstract ways ((Fischer \& Bidell, 2006; Inhelder \& Piaget, 1958). Harter (2012) proposes that the differentiation of abstract self-attributes starts to increase in early adolescence and, by middle adolescence, new cognitive skills allow the detection of inconsistencies between these abstract self-descriptions, thus promoting the perception of conflict within the self and the subsequent experience of negative affect (Fischer \& Kennedy, 1997; Harter \& Monsour, 1992). Provided that they have social support, some late adolescents can use integrative abstract skills to combine the seemingly contradictory self-attributes ("happy with close friend" and "annoyed with mother") in higher order self-attributes (e.g., "adaptable"). However, only in adulthood are these cognitive skills available to most people in a more autonomous way (Fischer \& Kennedy, 1997). Hence, transitory internalized symptoms may be an outcome of the organization of self-knowledge on its way towards a more elaborate and coherent self-system.

Some findings also provide evidence of a relation between identity changes (Erikson, 1968) and internalized symptoms. The exploration of alternative identities and low identity commitments is expected during adolescence, in the process of constructing an achieved 
personal identity (Marcia, 1980). Nevertheless, studies of adolescents and college students have linked higher levels of internalized symptoms with the identity status of moratorium (or higher levels of exploration) and the lack of commitments for a prolonged period of time (Kunnen, Sappa, van Geert \& Bonica, 2008; Luyckx, Schwartz, Goossens, Soenens \& Beyers, 2008; Meeus, 2011; Schwartz et al., 2010). In addition, there is evidence that better psychological adjustment becomes increasingly associated with strong identity commitments in late adolescence (e.g., Meeus et al., 2005). Furthermore, the identity status of foreclosure (which excludes previous significant exploratory activity) has been shown to be as healthy an “endpoint" in identity development as achievement (see Meeus, 2011). So, continued attempts at identity exploration may comprise a liability side, at least in later stages of adolescence, when commitments are needed to achieve well-being.

The process of "internalization of self-standards" has also been associated with psychological maladjustment in adolescence, as self-standards (the "ideal self”, for instance) and role models provided by significant others progressively give way to adolescents' own standards (Moretti \& Higgins, 1999; Zentner \& Renaud, 2007). Accordingly, several studies have reported that, during adolescence, the "ideal self" becomes increasingly distant from the self-perceived "actual self", from how others are perceived, and from the perceived "ideal self" that others have about the adolescent (Glick \& Zigler, 1985; Hankin, Roberts \& Gotlieb, 1997; Oosterwegel \& Oppenheimer, 1993; Pinquart, Silbereisen \& Wiesner, 2004; Strachan \& Jones, 1982; Zentner \& Renaud, 2007).

It is possible that these ambitious internalized self-guides play a very positive developmental role during adolescence in that they entail increased autonomy and provide guidance and motivation to pursue self-exploration and personal change (Makros \& McCabe, 2001; Markus \& Nurius, 1986; Moretti \& Higgins, 1999). However, some research shows that large distances between Actual and Ideal-selves can contribute to lower personal satisfaction 
with the self, or self-esteem (Harter, 2012; Pinquart et al., 2004), and promote depressive-like symptoms (Hammond \& Romney, 1995; Hankin et al, 1997; Higgins, 1987; Papadakis, Prince, Jones \& Strauman, 2006). This applies especially to older adolescents (Ferguson, Hafen \& Laursen, 2010). As Pinquart et al. (2004) found, the process of heightening an Ideal may be associated with lower self-esteem in older adolescents, because they set standards that are more difficult to accomplish in a reasonable amount of time (e. g., identity-related tasks can be more demanding than the task of making new friends). In addition, as Harter (2012) maintains, adolescents become less aware of the social origin of their standards, and older adolescents may grow less certain of their personal judgements.

In sum, several developmental gains emerge in middle to late adolescence concerning self-knowledge organization (self-differentiations, self-exploration for identity formation, individuation processes, internalization of self-standards, etc.) which have been associated with the increase in depressive-like symptoms throughout adolescence (which only decrease during adulthood) (e. g., Cicchetti \& Toth, 2009; Galambos, Barker \& Krahn, 2006; Hankin \& Abramson, 2001; Hankin et al., 1998; Harter, 2012). However, studies seldom consider a range of self-organization aspects (or, if they include them, they rely on different measurement instruments), thus hindering a comprehensive understanding of how they contribute to adaptation during adolescence (e.g., Campbell et al., 2003; Pilarska \& Suchańska, 2015). What is more, variables such as intrapersonal conflicts, which many theories regard as central, have been considered in only a few empirical studies (e.g., Harter \& Monsour, 1982; Oosterwegel \& Oppenheimer, 1993).

\section{Personal Construct Psychology, Self-knowledge and Psychological Adaptation}

According to Kelly (1955; for a comprehensive review, Walker \& Winter, 2007; Winter \& Reed, 2016), people, like scientists, construct hypotheses about objects, other persons, and events that are relevant to their adaptation and survival, and test them against 
experience. Applying this perspective, self-knowledge is seen as a system of bipolar constructs (or dimensions of meaning) based on perceived similarities and differences between self and others and between others (Jackson \& Bannister, 1985). Thus, according to PCP, knowledge about the self is entangled with knowledge about others, as recent approaches also propose (see, for instance, Chen, Boucher \& Kraus, 2011; Denny, Kober, Wager \& Ochsner, 2012).

Adaptive change is a main theoretical concern of PCP (see Chiari, 2016; Salmon, 1985), since it proposes that personal construct systems improve their ability to adequately anticipate events and guide a person in life. Pursuing this quest, self-knowledge, as a selforganizing system, evolves in the direction of increasing differentiation and hierarchical integration. Moreover, construct systems are conceived as being in constant motion. Kelly referred to the cyclic nature of construing to describe the continuous flow of psychological activity, as reflected in the cycle of experience. At each moment in their experience, people confront events; constructs are validated or, if not, their construct system is revised. This cyclic nature also includes the alternating use, in balanced ways, of construing processes such as dilation vs. constriction of the perceptual field, or loosening vs. tightening the ties between constructs and the assignment of constructs to elements as people try to make sense of daily events.

The experience we call emotions is also considered to be an integral part of the cycle of experience. In general, agreeable emotions (e. g., love, pride, self-confidence) are experienced when events validate the adequacy of the self-system or a part of it, and a negative emotional tone (e. g., anxiety, anger, sadness) may emerge when the facing of events makes evident the inadequacy of the self-system and signals a need for change (Butler \& Green, 2007; Kelly, 1955; for a review, Lester, 2009). So, emotions are considered a part of a healthy life and indispensable for development and change. In addition, psychological 
disorders are perceived as reflecting an imbalance in the process of construing (Winter, 2003). In particular, the construing of depressed people has been described as more constricted, less differentiated, and more polarized; showing a negative bias, a fatalistic view of the future; and a perception of the self as isolated from others (e.g., Feixas, Erazo-Caicedo, Harter \& Bach, 2008; Kelly, 1955; Neimeyer, 1984; Sanz, 1992).

(Insert Figure 1 about here)

A related contribution of Kelly's work is the repertory grid technique (RGT), a procedure designed for the assessment of the structure of personal construct systems (for a description of the technique in its current form see Feixas \& Cornejo, 2002; Fransella, Bell \& Bannister, 2004). Compared to more traditional instruments, the RGT has the advantage of providing idiographic self-knowledge (both content and structure) and, at the same time, quantitative measures with already studied psychometrical properties (see Fransella et al., 2004).

Overall, Kelly's approach offers a promising, comprehensive framework, both theoretical and methodological, for the analysis of a range of psychological constructs concerning the organization of self-knowledge during adolescence (e. g., global differentiation; discrepancies between Actual Self, Ideal Self and Others, or self-esteem, individuation, identification and identity formation, internalization of self-standards; intrapersonal conflicts, etc.) and its relation with depression (e.g., Hammond \& Romney, 1995; Jablonski \& Lester, 2008; Jackson \& Bannister, 1985; Oosterwegel \& Oppenheimer, 1993; Strachan \& Jones, 1982). Moreover, the RGT allows the identification of internal conflicts (Feixas, Saúl \& Ávila-Espada, 2009), a variable that is seldom present in empirical research.

\section{The Present Study}


The aim of this study is to explore the relations between diverse aspects of selfknowledge organization and depressive symptoms in late adolescence, considering the predictions from developmental perspectives explained above and the PCP's conceptual devices (such as the entanglement of knowledge about the self and about significant others, or the transitions in the self-system and emotional experience) and methodological devices (such as a set of structural measures derived from the RGT).

The study's general developmental hypothesis is that organization of self-knowledge will differ in adolescents with or without depressive symptomatology, in so far as those with higher depressive levels would show a developmentally more sophisticated organization of self-knowledge. In particular, adolescents with depressive symptoms are expected to show a globally more differentiated self-knowledge and larger mean discrepancies between Actual and Ideal selves (or lower self-esteem), Actual self and Others (or lower identification with others) and Ideal self and Others (a more negative view of others, or a more isolated ideal self). The adolescents with depressive symptoms are also expected to show lower polarization and a greater likelihood of intrapersonal conflicts. A complementary hypothesis proposes that there will be stronger relationships between measures of self-structure and symptoms in the sample with high levels of depression than in the sample without symptoms.

\section{Method}

\section{Participants}

Participants were selected from a larger sample $(\mathrm{N}=357)$ of $12^{\text {th }}$ grade students in three secondary schools in a town in southern Portugal, who presented statistically extreme scores on a depressive symptoms inventory. Thirty-five adolescents participated in the final sample: 19 (2 boys and 17 girls, $\left.\mathrm{M}_{\mathrm{age}}=17.6, \mathrm{SD}=1.01\right)$ comprised the Depression group (D), and $16\left(9\right.$ boys and 7 girls, $\left.\mathrm{M}_{\mathrm{age}}=17.3, \mathrm{SD}=1.14\right)$ the No-Symptoms group (NS).

\section{Instruments}


Children's Depression Inventory (CDI). The CDI (Kovacs, 1992; Portuguese version by Marujo, 1994) comprises 27 items concerning a diversity of symptoms related to depression. This Portuguese version includes four options for assessing symptom severity, from 0 (absence of symptom) to 3 (greatest severity). The adaptation study in Portuguese children and adolescents (community samples) showed Cronbach alpha values of .83 and .90 (Marujo, 1994).

Brief Symptom Inventory (BSI). The BSI (Derogatis, 1982; Portuguese version by Canavarro, 1999a) has 53 items which are rated from 0 (not at all) to 4 (extreme), providing measures of nine dimensions of psychopathology: somatization (S), obsession-compulsion (OC), interpersonal sensitivity (IS), depression (Dp), anxiety (A), hostility (H), phobic anxiety (PA), paranoid ideation (PI), and psychoticism (Ps). A global measure was also considered, the Positive Symptom Distress Index (PSDI): above the cut-off point of 1.7, this measure is considered to signal a high probability of emotional distress (Canavarro, 1999b). This version has shown adequate psychometric properties including internal consistency, with Cronbach alphas ranging from $.62(\mathrm{Ps})$ to $.80(\mathrm{~S})$.

Repertory Grid Technique (RGT). Each adolescent filled in a repertory grid of 15 elements $\times 12$ constructs, in a structured group procedure similar to an interview. First, the participants identified a sample of significant others (Father, Mother, Brother or Sister/the closest in age, Friend/same gender, Friend/other gender, Boyfriend/Girlfriend/romantic interest, Liked Person, Disliked Person) and self (Actual, Self as perceived by father, Self as perceived by mother, Self as perceived by best friend, Ought Self, Probable Self/one year later, and Ideal Self) elements. Second, bipolar constructs (e.g., responsible vs. irresponsible) were elicited using the dyadic method: participants were asked to compare a pair of elements (e.g., Actual Self and Father) looking for similarities (e.g. "which characteristics do these two people have in common?", then asking for the opposite of that characteristic) and then for 
differences (e.g., "and in which characteristics are they different?"). Finally, a 7-point Likert scale was used to score each element in each construct: scores of 1-very much so, 2-quite a lot, and 3-a little, applied to the first pole of the construct (e.g., responsible); scores of 5-a little, 6-quite a lot, and 7-very much so, applied to the other pole (e.g., irresponsible); the 4middle point was used only when a participant was unable to rate an element on either construct pole. Six structural measures were computed from each individual data matrix, which are described below (for details on the psychometric properties of the repertory grid and its measures, see Feixas, Bach \& Laso, 2004; Feixas \& Cornejo, 2002; Fransella et al., 2004; Neimeyer \& Feixas, 1992; Winter, 1992).

Percentage of variance accounted for by the first factor (PVFF). This measure of global differentiation (see Feixas et al., 2004) quantifies the most important dimension of meaning, following a principal components analysis of each individual grid. Lower values have been interpreted as indicating higher differentiation (i.e., a multidimensional interpretation of self and others), and higher values as indicating one-dimensional construing.

Polarization (P). This measure computes the percentage of extreme scores (1 and 7$)$ in the grid: it is a measure of "all or nothing" thinking (Feixas et al., 2004). (Insert Figure 1 about here)

Presence of implicative dilemmas (ID). An implicative dilemma is a cognitive conflict about personal change; its presence in a repertory grid is identified by a correlation (of at least .35) between a congruent construct (Actual and Ideal selves perceived as similar, score difference no higher than 1 point) and a discrepant construct (Actual and Ideal selves perceived as different, score difference higher than 3 points) (Feixas et al., 2009). This correlation between a congruent and a discrepant construct is considered indicative of a conflictive structure when the desired change expressed by the discrepant construct is associated with the undesired pole of the congruent construct. In the example in Figure 1, an 
adolescent saw himself as "introverted" but wished to become "extroverted" (as indicated by the position of the Ideal self). He also considered himself as "sensitive"; in this regard he conformed to his "ideal self", and therefore becoming "insensitive" would invalidate a selfperceived positive attribute. The dilemma appears when, as inferred from the correlations among the construct scores, the change in the direction of becoming extroverted is linked, in his construct system, to becoming more insensitive - an undesirable goal. In this study the dichotomous variable presence or absence of IDs was considered.

Recently, it has been found that IDs are more often present in adults diagnosed with depressive disorders and other clinical conditions (Montesano, López-González, Saúl \& Feixas, 2015), and that people with IDs showed higher severity of depressive and anxiety symptoms in a community sample (Saúl, López-González, Feixas, Rubio-Garay \& Domínguez-Simón 2014). Furthermore, despite the higher incidence in clinical samples (in different studies, $52 \%$ to $70 \%$ of subjects showed at least one dilemma), the presence of IDs in nonclinical samples was quite high (34\% to 39\%) (Feixas et al., 2009; Feixas et al., 2014a; Feixas, Montesano, Erazo-Caicedo, Compañ \& Pucurull, 2014b; Montesano et al., 2014; Saúl et al., 2014). A recent study (Carapeto \& Feixas, 2017) found that IDs were more likely in late adolescents (60\%) than adults, in girls than boys (68\% vs. $42 \%)$, and in late than early adolescents (60 vs. 39\%). No data are available for depressed adolescents in this measure.

Discrepancies between Actual Self, Ideal Self and Others (A-I, A-O, and I-O). By computing mean Euclidian distances between the scores of the Actual Self(A), Ideal Self (I) and Others $(\mathrm{O})$ (Father, Mother, Brother/Sister, Friend/same gender, Friend/other gender, Boyfriend/Girlfriend, Liked Person, and Disliked Person) three self-discrepancy measures were obtained: A-I, A-O, and I-O. These can be considered measures of cognitive differentiation (Glick \& Zigler, 1985; Oosterwegel \& Oppenheimer, 1993), such that the greater the distance, the greater the differentiation. Also, the A-I is considered a self-esteem 
measure (Feixas et al., 2008; Wang \& Ollendick, 2001), such that the greater the distance, the lower the self-esteem.

The A-O discrepancy has been used as a measure of identification with others, along a continuum from self-perception of social isolation of the self (greater distance) to identification with others (lesser distance) (Feixas et al., 2008; Strachan \& Jones, 1982).

Finally, the I-O has been conceived as a measure of the perceived adequacy of Others, going from a favorable perception (lesser distance) to a perception of Others' inadequacy (greater distance) (Feixas et al., 2008). It has also been used as a measure of how much the Ideal is inspired (lesser distance) or isolated (greater distance) from Others (Strachan \& Jones, 1982).

\section{Procedures}

After obtaining informed consent from the schools' Principals, adolescents, and their parents, the first of the two phases of data collection began. During this first phase, two inventories of symptoms were administered to $35712^{\text {th }}$ graders during class time. Statistically extreme scores on the CDI were then used to identify the adolescents for the final D and NS samples. Fifty-nine participants with minimum scores of one standard deviation above the mean $(>25.40+7.15)$ were selected for the D sample, and 52 participants with maximum scores of one standard deviation below the mean $(<25.40-7.15)$ and a PSDI lower than 1.7 (one case excluded) made up the NS sample. The adolescents selected were asked by phone to participate in the second phase of data collection, and 35 agreed. At the end, the D final sample scored significantly higher on all symptom measures (Table 1). The second phase of data collection was carried out some days later and consisted in the administration of the RGT to small groups of up to eight adolescents, in a school classroom outside class time.

Two computer programs were used to analyse the data: the GRIDCOR, version 4.0 (Feixas \& Cornejo, 2002) and the IBM SPSS 21. The first program was designed to analyse 
grid data and was used to compute the self-knowledge structural measures from each repertory grid.

The use of the SPSS for the statistical analysis highlighted the differences between D and NS adolescents in the measures of self-knowledge organization. Since samples were small, we followed the strategy suggested by Fife-Schaw (2006): parametrical tests and their equivalent non-parametrical tests were performed and, as both led to the same conclusions regarding statistical inference, the results of the parametrical tests were used. First, a multivariate analysis of variance (MANOVA) was performed to check the general hypothesis that, overall, D and NS organize self-knowledge differently. All five quantitative measures were entered as dependent variables and gave rise to the composite variable "structure of selfknowledge". One factor was considered: the Group (in two categories, D and NS). Because a difference was found between the two samples in the composite variable of "structure of selfknowledge", a series of analyses of variance (ANOVA) were computed to assess the effect of Group on each quantitative measure. For IDs, a statistical analysis for categorical variables was carried out. A logistic regression was also performed to explore the relative effectiveness of each structural measure to predict whether an adolescent would belong to one or other group (D or NS). Correlations between self-organization measures (point-biserial correlations, for ID) and symptom severity were computed for each sample.

(Insert Table 1 about here)

\section{Results}

Statistically significant results from the MANOVA indicated that D and NS had different self-knowledge structures, $F(5,29)=5.2, p=.002 ; \eta^{2} \mathrm{p}=.475$, and the follow-up ANOVA tests suggested that the groups were similar with regard to P, A-O and I-O (Table 1). In addition, D showed lower PVFF (higher global differentiation) and higher A-I (lower selfesteem) than NS. As for conflicts within the self, $74 \%$ of the adolescents in the D group 
presented at least one ID compared with a significantly lower proportion (25\%) in the NS group.

A logistic regression was performed entering Group as dependent variable and all six self-organization measures as independent variables. The forward stepwise (likelihood ratio) method was used. The analysis was completed after performing the first step, and presence of IDs emerged as the only predictor, Wald $=7.490, d f=1, p=.006, \operatorname{Exp}(B)=8.400$. Accordingly, IDs were able to correctly classify $74.3 \%$ of the 35 adolescents into their D or NS group. This model incorporating IDs fits the data better than a model without predictors (Omnibus test of model coefficients, $\left.\chi^{2}(1,35)=8.596, p=.003\right)$ and explains $29.1 \%$ of variance in the dependent variable (Nagelkerke's $R^{2}=0.291$ ). (Insert Table 2 about here)

The complementary analysis of the correlations between self-knowledge organization measures and symptom severity is presented separately for the D and NS samples in Table 2 . Overall, only P and I-O (with similar mean values for both D and NS) did not correlate with the severity of symptoms, and, among symptom measures, only PA did not correlate with any self-knowledge measure. In the D group, more correlations reached statistical significance (12 out of 55) than in the NS group (two).

The A-O means were similar for both samples, but varied in the D sample according to severity of symptoms. In the D sample as well, but not in the NS sample, the presence of ID correlated with severity of symptoms, OC and PI.

In the NS group, the isolated associations of the PVFF and PSDI and CDI were salient: higher symptom severity and higher global differentiation went together. In depressed adolescents, this self-knowledge measure was associated with $\mathrm{H}$ only (i.e., the greater the differentiation, the greater the hostility symptoms).

\section{Discussion}


The results support our general hypothesis that late adolescents with and without depressive symptomatology organize self-knowledge differently, and that there are links between self-knowledge organization and internalized maladjustment in this stage of life, especially in adolescents with depression. In particular, compared to adolescents without symptoms, those with depressive symptoms showed higher global self-knowledge differentiation (lower PVFF), higher A-I (or lower self-esteem), and presented implicative dilemmas more frequently. The effect sizes reported should encourage further research to confirm or extend on the present analysis. Among all the self-structure variables studied, some evidence was found of the singular role of the presence of IDs in predicting adolescents' belonging to one or other sample. However, some of our hypotheses were not supported, since no significant differences were found in self-differentiation from others (both A-O, or identification, and I-O, or Ideal inspired by others or perceived adequacy of others) or in P (although the differences were in the expected direction).

The higher global differentiation in construing self and others found for the depressive adolescent sample is consistent with the cognitive-developmental perspective (e.g., Fischer \& Kennedy, 1997; Harter, 2012), and with recent research on self-complexity (e.g., Cohen, Spiegler, Young, Hankin \& Abela, 2013), as well as with recent results in the PCP field (e.g., Feixas et al., 2008). But this finding is at odds with the theory and with reports associating higher self-knowledge differentiation with better adjustment (e.g., Evans, 1994; Kelly, 1955; Linville, 1987; Neimeyer, 1984). The higher global differentiation of adolescents with depressive symptoms indicates that they have more dimensions of meaning with which to interpret themselves and others, which seems to be a developmental, adaptive advance. However, it is possible that high global self-differentiation may, at this stage, be a fertile ground for the emergence of inconsistencies among so much differentiated self-knowledge (or intrapersonal conflict, an issue to be analysed below), and internalized, depressive-like 
symptoms as well (e.g., Harter, 2012). This notion is also supported by the results of the adolescents without symptoms, in whom higher global differentiation was associated with more severe depressive symptoms. If so, as soon as adolescents can use integrative skills to organize a more coherent self-picture, they may be freed from this maladjustment. This issue deserves further assessment in longitudinal studies.

The results also challenge the classic stress-buffering hypothesis of higher selfdifferentiation (Linville, 1987), but are compatible with more recent findings and ideas in the field of self-complexity (e.g., Brown \& Rafaaeli, 2007; Cohen et al., 2013). For instance, Cohen et al. (2013) found that in the absence of identified stressors, higher self-complexity (or at least some of its components) may be related to depression. The moderating role of selfdifferentiation in face of stressors is an issue that should be explored in further studies, as we did not collect data about possible stressful events. However, other research (see, for instance, Hankin \& Abramson, 2001) has shown that adolescents with high scores on depression also reported a higher amount of stressful events. It is possible that the depressed adolescents dynamically increased self-knowledge differentiation so as to buffer the negative impact of those possible events (e.g., Brown \& Rafaeli, 2007; Cohen et al., 2013; Showers \& ZeiglerHill, 2003). The null correlation between PVFF and CDI found for the D group (together with the correlation found for the NS groups) offers some support to this proposal: once a certain high level of differentiation was attained, a buffer effect was noticed and the severity of depression no longer increased.

At first glance, this result contradicts the PCP hypothesis that depressed people show a more constricted, less differentiated self-system (e.g., Kelly, 1955; Neimeyer, 1984). Actually, the research carried out until now, mainly in adult samples, has not reached a consensus on this issue, suggesting that the relationship between depression and selfknowledge differentiation may not be a linear one (e.g., Feixas et al., 2008; Sanz, 1992). As 
suggested by Sanz (1992), it is possible that the organization of self-knowledge evolves over the course of depressive trajectories, beginning with an increase in self-differentiation in the initial stages (or sub-clinical levels), and progressively moving towards a more onedimensional construing as individuals move into more severe depression. This explanation seems to be particularly apposite during middle to late adolescence, a period when the emergence of depression is relatively frequent (e.g., Hankin et al, 1998).

An additional explanation emerges when considering this possible developmental trajectory of depression in the broader context of adolescent development (Coleman, 2011). Kelly (1955) defined two different dimensions of construing in transitions: loosening vs. tightening, and dilation vs. constriction. Higher global differentiation could mean more dilated and/or more loosened construing. Dilation could be perceived as a first step towards a necessary hierarchical integration, by allowing adolescents to expand their perceptual field and to try to consider simultaneously a larger number of elements from their personal and interpersonal world. Loosening may offer an opportunity to construct new meanings for the numerous new contexts in adolescent life, by weakening the ties between constructs and the previous assignment of these constructs to personal and interpersonal elements. In this context, depressive symptoms could signal a need for balance (Winter, 2003), the need to form high order constructs inspired by a diversity of elements and to reduce dilation, and/or to tighten construing to test new meanings against reality and thus complete the creativity cycle. Possibly, late adolescents with depression have difficulty in self-regulating this balance. In the end, a high level of differentiation may be experienced as fragmentation (Cohen et al., 2013; Feixas et al, 2009; Kelly, 1955).

The IDs proved to be the most powerful of our measures for distinguishing between depressed and non-symptomatic adolescents, as their presence was more frequent in the depressed group (74\% vs. $25 \%$ ). This result is in line with the developmental hypothesis 
mentioned above (together with the global differentiation findings) and with recent studies in clinically depressed and non-clinical adults (Feixas et al., 2014a; Feixas, Montesano, ErazoCaicedo, Compañ \& Pucurull, 2014; Montesano et al., 2014; Montesano, López-González, Saúl \& Feixas, 2015; Saul et al., 2014). Yet, adolescents in the D sample were also more likely (and NS adolescents less likely) to present IDs than late adolescents from the general population (60\% in Carapeto \& Feixas, 2017).

Correlational analysis showed that depressed adolescents with dilemmas reported more severe paranoid ideation and obsession-compulsion symptoms, the two BSI scales most closely related to cognitive conflict. These results mirror those of Harter and Monsour (1992), who also found no negative affect other than the feeling "mixed or confused" in adolescents reporting conflicts. It may be that, in adolescents with depressive symptoms, IDs combine with a ruminative style that has been described as a vulnerability factor for depression (e.g., Cox, Funasaki, Smith \& Mezulis, 2012; Hankin \& Abramson, 2001; Hilt \& Pollak, 2013; Kuyken, Watkins, Holden \& Cook, 2006; Papadakis et al., 2006). The presence of IDs may contribute to psychological malaise, encourage rumination, and, simultaneously, activate a personal effort to build a more coherent self-system. Adolescents without symptoms with IDs did not report higher severity of any symptoms, possibly because they were less aware of these conflictive structures or because they were less prone to rumination. So it is possible that IDs contribute to depression.

The possible role of IDs in promoting or blocking personal change at a developmental stage like adolescence in which numerous changes are expected (e.g., Coleman, 2011), and their influence on depression trajectories merits further research. Indeed, in an adult community sample the presence of ID was associated with severe depressive and anxiety symptoms (Saúl, López-González, Feixas, Rubio-Garay, Domínguez-Simon, 2014), but not with those of a more cognitive kind found in the D sample, and IDs were also associated with 
openness to experience (see Saúl et al., 2014).

With regard to the self-discrepancies, the higher A-I found for depressed adolescents is consistent with previous studies with adolescents (e.g., Hammond \& Romney, 1995; Hankin et al., 1997) and adults (e.g., Feixas et al, 2008). This result suggests that D adolescents may use more advanced skills concerning cognitive differentiation or the internalization of ideals (e.g., Glick \& Zigler, 1985). Also, the more ambitious standards for personal change that they seemed to establish (Moretti \& Higgins, 1999; Pinquart et al, 2004) were possibly more fantastical and hard to attain and, thus, possibly contributed to lower selfesteem. As such, this high level of discrepancy can be experienced as internalized maladjustment (Ferguson et al., 2010; Higgins, 1987; Pinquart et al., 2004). This discrepancy emerges as a possible risk factor for present and future adjustment, as low self-esteem can favor a trajectory of depression into adulthood (e.g., Compas, Connor \& Heiden, 1998; Orth, Robins \& Roberts, 2008; Steiger, Fend \& Allemand, 2015) and A-I may stabilize at the end of adolescence (Zentner \& Renaud, 2007).

Contrary to our hypotheses, no significant differences in the self-differentiation from others (both A-O and I-O) were found. In this respect, the results paralleled those of Feixas et al. (2008) in a sample of adults with adjustment disorder with depressive mood. It seems that both samples identified themselves with others and perceived the adequacy of others to a similar degree, and that significant others played a similar role as self-standards. However, the A-O was associated with the severity of depressive symptoms for the already depressed adolescents, for whom lower identification was associated with more severe symptoms; it is possible that adolescents obtain some degree of protection for depression when they can identify themselves with others.

Finally, D and NS samples presented similar results for polarization. This is consistent with Hammond and Romney's (1995) study and with some studies in adult samples (e.g., 
Feixas et al, 2008; Sanz, 1992). Nevertheless, although the difference did not reach statistical significance, depressed adolescents had a lower level of polarization, as our developmental hypothesis predicted.

\section{Conclusions}

Among other methodological limitations the small size of our samples and the absence of a clinical comparison group recommend caution in drawing conclusions. In spite of these caveats this exploratory study presents some interesting insights. First, depressed late adolescents organize self-knowledge differently from their non-symptomatic peers. Furthermore, some aspects of the organization of self-knowledge are associated with adjustment, in particular in depressed adolescents. The possibility that a more sophisticated self-knowledge organization (though as yet not able to achieve optimal integration) contributes to the formation of conflictive structures and (transitory) depressive symptomatology among middle and late adolescents (e.g., Harter, 2012; Noam et al., 1994) received some support from our study. Because depressive experience and low self-esteem seem to be risk factors for several developmental outcomes including depressive trajectories to adulthood (e.g., Compas et al., 1998; Orth et al., 2008; Steiger et al., 2015), some practical implications of our study should be stressed. In particular, adolescents need to have appropriate social support (including clinical and psychological counselling) to help them in the tasks of reorganizing self-knowledge in more integrative ways (Fischer \& Kennedy, 1997; Harter, 2012) and regulating actual/ideal self-discrepancies (Zentner \& Renaud, 2007). The role of peers may have a limited (or even a deleterious) effect in these tasks, as some recent studies about co-rumination have suggested (Dirghangi et al., 2015; Stone, Hankin, Gibb \& Abela, 2011). Additional research is needed to clarify the developmental trajectories of selfknowledge organization, stressful events and psychological maladjustment throughout adolescence and adulthood, in particular by means of longitudinal studies that include clinical, 
sub-clinical and normal samples. The present exploratory study reinforces the potential of reciprocal contributions from developmental approaches and PCP for reaching a more comprehensive understanding of the complexities of self-knowledge and its relation to depressive mood throughout adolescence. 


\section{References}

Brown, G. \& Rafaeli, E. (2007). Components of Self-Complexity as Buffers for Depressed Mood. Journal of Cognitive Psychotherapy, 21(4), 310-333. Doi: $10.1891 / 088983907782638761$

Butler, R. J. \& Green, D. (2007). The child within. Taking the young person's perspective by applying Personal Construct Psychology ( $2^{\text {nd }}$ Ed.). Chichester, UK: Wiley.

Campbell, J. D., Assanand, S. \& Paula, A. D. (2003). The structure of the self-concept and its relation to psychological adjustment. Journal of Personality, 71(1), 115-140. doi: 10.1111/1467-6494.t01-1-00002

Canavarro, M. C. (1999a). Inventário de Sintomas Psicopatológicos - BSI. In M. R. Simões, M. Gonçalves \& L. Almeida (Eds), Testes e Provas Psicológicas em Portugal (Vol. II) (pp. 95-109). Braga, Portugal: Sistemas humanos e Organizacionais.

Canavarro, M. C. (1999b). Relações Afectivas e Saúde Mental. Coimbra, Portugal: Quarteto.

Carapeto, M.J.; \& Feixas, G. (2017). Self-Knowledge in Adolescence: a study using the repertory grid technique. Manuscript submitted for publication.

Chen, S., Boucher, H. \& Kraus, M. W. (2011). The relational self. In S. J. Schwartz, K. Luyckx \& V. L. Vignoles (Eds.), Handbook of identity theory and research (pp. 149175). New York, N.Y.: Springer.

Chiari, G. (2016). To Live Is to Know, to Know Is to Change: Change in Personal Construct Psychology and Psychological Constructivism. Journal of Constructivist Psychology, 29, 340-356. DOI:10.1080/10720537.2015.1134364

Cicchetti, D. \& Toth, S. L. (2009). A developmental psychopathology perspective on adolescent depression. In S. Nolen-Hoeksema and L. M. Hilt (Eds.), Handbook of depression in adolescents (pp. 3-31). New York, NY: Routledge.

Cohen, J. R., Spiegler, K. M., Young, J. F., Hankin, B. L. \& Abela, J. R. (2013). Self- 
structures, negative events, and adolescent depression clarifying the role of selfcomplexity in a prospective, multiwave study. The Journal of Early Adolescence, 34(6), 736-759. DOI:10.1177/0272431613503217

Coleman, J. C. (2011). The Nature of Adolescence ( $4^{\text {th }}$ Ed.). London / New York: Routledge.

Compas, B. E., Connor, J. K. \& Heiden, B. R. (1998). New perspectives on depression during adolescence. In R. Jessor (Ed.). New perspectives on adolescent risk behaviour (pp. 319-362). Cambridge, U.K.: Cambridge University Press.

Cox, S., Funasaki, K., Smith, L. \& Mezulis, A. H. (2012). A prospective study of brooding and reflection as moderators of the relationship between stress and depressive symptoms in adolescence. Cognitive Therapy and Research, 36(4), 290-299. DOI:10.1007/s10608-011-9373-Z

Damon, W. \& Hart, D. (1988). Self-understanding in childhood and adolescence. New York: Cambridge University Press.

Denny, B. T., Kober, H., Wager, T. D. \& Ochsner, K. N. (2012). A meta-analysis of functional neuroimaging studies of self-and other judgments reveals a spatial gradient for mentalizing in medial prefrontal cortex. Journal of Cognitive Neuroscience, 24(8), 1742-1752. Doi:10.1162/jocn_a_00233

Derogatis, L. (1982). BSI: Brief Symptom Inventory. Minneapolis: National Computers Systems.

Dirghangi, S., Kahn, G., Laursen, B., Brendgen, M., Vitaro, F., Dionne, G. \& Boivin, M. (2015). Co-rumination cultivates anxiety: A genetically informed study of friend influence during early adolescence. Developmental psychology, 51(4), 564. doi: $10.1037 / \mathrm{a} 0038848$

Erikson, E. H. (1968). Identity: Youth and crisis. New York: Norton.

Evans, D. W. (1994). Self-Complexity and Its Relation to Development, Symptomatology and 
Self-Perception During Adolescence. Child Psychiatry and Human Development, 24, 173-182. DOI:10.1007/BF02353194

Feixas, G., Bach, L. \& Laso, E. (2004). Factors affecting interpersonal construct differentiation when measured using the Repertory Grid. Journal of Constructivist Psychology, 17, 297-311. DOI:10.1080/10720530490483202

Feixas, G. \& Cornejo, J. M. (2002). GRIDCOR v. 4.0: Correspondence analysis of personal constructs. Barcelona: Psimedia. Available at www.terapiacognitiva.net/record

Feixas, G., Erazo-Caicedo, M. I., Harter, S. L. \& Bach, L. (2008). Construction of Self and Others in Unipolar Depressive Disorders: A Study Using Repertory Grid Technique. Cognitive Therapy and Research, 32, 386-400. doi:10.1007/s10608-007-9149-7

Feixas, G., Montesano, A., Compan, V., Salla, M., Dada, G., Pucurull, O., ... \& Saúl, L. Á. (2014a). Cognitive conflicts in major depression: Between desired change and personal coherence. British Journal of Clinical Psychology, 53(4), 369-385.

DOI: $10.1111 /$ bjc. 12050

Feixas, G., Montesano, A., Erazo-Caicedo, M. I., Compañ, V. \& Pucurull, O. (2014b). Implicative dilemmas and symptom severity in depression: a preliminary and content analysis study. Journal of Constructivist Psychology, 27(1), 31-40. DOI:10.1080/10720537.2014.850369

Feixas, G., Saúl, L. A. \& Ávila-Espada, A. (2009). Viewing cognitive conflicts as dilemmas: implications for mental health. Journal of Constructivist Psychology, 22, 141-169. DOI:10.1080/10720530802675755

Ferguson, G. M., Hafen, C. A. \& Laursen, B. (2010). Adolescent Psychological and Academic Adjustment as a Function of Discrepancies Between Actual and Ideal SelfPerceptions. Journal of Youth and Adolescence, 39, 1485-1497. DOI: 10.1007/s10964$009-9461-5$ 
Fife-Schaw, C. (2006). Levels of measurement. In G. M. Breakwell, S. Hammond, C. FifeSchaw \& J. A. Smith (Eds.), Research Methods in Psychology ( ${ }^{\text {rd }}$ Ed.) (pp. 50-63). London, U.K.: Sage.

Fischer, K. W. \& Bidell, T. R. (2006). Dynamic Development of Action and Thought. In W. Damon e R. M. Lerner (Eds.). Theoretical Models of Human Development. Handbook of Child Psychology (6 ${ }^{\text {th }}$ Ed., Vol. 1, pp. 313-399). New York: Wiley.

Fischer, K. W. \& Kennedy, B. P. (1997). Tools for analysing the many shapes of development: the case of self-in-relationships in Korea. In E. Amsel \& K. A. Renninger (Eds.), Change and Development: Issues of Theory, Method and Application. The Jean Piaget Symposium Series (pp. 117-152). Mahwah, NJ: Lawrence Erlbaum.

Fransella, F., Bell, R. \& Bannister, D. (2004). A Manual for Repertory Grid Technique (2 ${ }^{\text {nd }}$ Ed.). Chichester, UK: Wiley.

Galambos, N. L., Barker, E. T. \& Krahn, H. J. (2006). Depression, Self-Esteem, and Anger in Emerging Adulthood Seven-Year Trajectories. Developmental Psychology, 42, 350365. DOI: 10.1037/0012-1649.42.2.350

Glick, M. \& Zigler, E. (1985). Self-image: a cognitive-developmental approach. In R. L. Lehary (Ed.), The development of the self (pp. 1-53). London: Academic.

Hankin, B. L. (2015). Depression from childhood through adolescence: Risk mechanisms across multiple systems and levels of analysis. Current Opinion in Psychology, 4, 1320. Doi:10.1016/j.copsyc.2015.01.003

Hankin, B. L. \& Abramson, L. Y. (2001). Development of Gender differences in depression: an elaborated cognitive vulnerability - transactional stress theory. Psychological Bulletin, 127, 773-796. Doi:10.1037/0033-2909.127.6.773 
Hankin, B. L., Abramson, L. Y., Moffitt, T. E., Silva, P. A., McGee, R. \& Angell, K. A. (1998). Development of Depression from Preadolescence to Young Adulthood: Emerging Gender Differences in a 10-Year Longitudinal Study. Journal of Abnormal Psychology, 107, 128-140. Doi:10.1037/0021-843X.107.1.128

Hankin, B. L.; Roberts, J.; \& Gotlib, I. H. (1997). Elevated self-standards and emotional distress during adolescence: emotional specificity and gender differences. Cognitive Therapy and Research, 21, 663-679. doi:10.1023/A:1021808308041

Hammond, W. A.; \& Romney, D. M. (1995). Cognitive factors contributing to adolescent depression. Journal of Youth and Adolescence, 24, 667-683. doi:10.1007/BF01536950

Harter, S. (2012). The Construction of the Self: Developmental and Sociocultural Foundations ( $2^{\text {nd }}$ Edition). New York, N. Y.: Guilford.

Harter, S. \& Monsour, A. (1992). Developmental analysis of conflict caused by opposing attributes in the adolescent self-portrait. Developmental Psychology, 28, 251-260. Doi:10.1037/0012-1649.28.2.251

Higgins, E. T. (1987). Self-discrepancy: A theory relating self and affect. Psychological Review, 94, 319-340. Doi:10.1037/0033-295X.94.3.319

Hilt, L. M. \& Pollak, S. D. (2013). Characterizing the ruminative process in young adolescents. Journal of Clinical Child \& Adolescent Psychology, 42(4), 519-530. DOI: $10.1080 / 15374416.2013 .764825$

Inhelder, B. \& Piaget, J. (1958). The Growth of Logical Thinking from Childhood to Adolescence. New York: Basic Books.

Jablonski, J. F. \& Lester, D. (2008). Incorporating development into personal construct theory. Personal Construct Theory \& Practice, 5, 41-48.

Jackson, S. R. \& Bannister, D. (1985). Growing into self. In D. Bannister (Ed), Issues and approaches in personal construct psychology (pp. 67-82). London: Academic Press. 
Lester, D. (2009). Emotions in personal construct theory: A review. Personal Construct Theory \& Practice, 6, 90-98.

Linville, P. W. (1987). Self-complexity as a cognitive buffer against stress-related illness and depression. Journal of Personality and Social Psychology, 52(4), 663. doi:10.1037/0022-3514.52.4.663

Kelly, G. A. (1955). The Psychology of Personal Constructs. New York: Norton.

Kovacs, M. (1992). Children's depression inventory. New York: Multi-Health Systems.

Kovacs, M. \& Devlin, B. (1998). Internalizing disorders in childhood. Journal of Child Psychology and Psychiatry, 39(01), 47-63.

Kunnen, E. S., Sappa, V., van Geert, P. L. C. \& Bonica, L. (2008). The Shapes of Commitment Development in Emerging Adulthood. Journal of Adult Development, 15, 113-131. doi:10.1007/s10804-008-9042-y

Kuyken, W., Watkins, E., Holden, E. \& Cook, W. (2006). Rumination in adolescents at risk for depression. Journal of Affective Disorders, 96, 39-47.

Doi:10.1016/j.jad.2006.05.017

Luyckx, K., Schwartz, S. J., Goossens, L., Soenens, B. \& Beyers, W. (2008). Developmental typologies of identity formation and adjustment in female emerging adults: A latent class growth analysis approach. Journal of Research on Adolescence, 18(4), 595-619. DOI: $10.1111 / \mathrm{j} .1532-7795.2008 .00573 . x$

Makros, J. \& McCabe, M. (2001). Relationships between identity and self-representations during adolescence. Journal of Youth and Adolescence, 30, 623-639.

DOI:10.1023/A:1010404822585

Marcia, J. (1980). Identity in Adolescence. In Adelson, J. (Ed.). Handbook of Adolescent Psychology (pp. 159-187). New York: Wiley. 
Markus, H. R. \& Nurius, P. (1986). Possible Selves. American Psychologist, 41, 954-969. Doi:10.1037/0003-066X.41.9.954

Marujo, H. A. (1994) Síndromas depressivos na Infância e na Adolescência. Non published Doctoral Dissertation. Lisboa, Portugal: Faculdade de Psicologia e Ciências da Educação.

Meeus, W. (2011). The study of adolescent identity formation 2000-2010: A review of longitudinal research. Journal of Research on Adolescence, 21(1), 75-94. DOI:10.1111/j.1532-7795.2010.00716.x

Meeus, W., Iedema, J., Maassen, G. \& Engels, R. (2005). Separation-individuation revisited: on the interplay of parent-adolescent relations, identity and emotional adjustment in adolescence. Journal of Adolescence, 28, 89-106.

DOI:10.1016/j.adolescence.2004.07.003

Montesano, A., Feixas, G., Saúl, L. A., Caicedo, M. I. E., Dada, G. \& Winter, D. (2014). Cognitive conflicts and symptom severity in dysthymia: "I'd rather be good than happy". Salud Mental, 37(1), 41-48.

Montesano, A., López-González, M. A., Saúl, L. A. \& Feixas, G. (2015). A review of cognitive conflicts research: a meta-analytic study of prevalence and relation to symptoms. Neuropsychiatric Disease and Treatment, 11, 2997.

Doi:10.2147/NDT.S91861

Moretti, M. \& Higgins, E. (1999). Own versus other standpoints in self-regulation: Developmental antecedents and functional consequences. Review of General Psychology, 3, 188-223. DOI: 10.1037/1089-2680.3.3.188

Neimeyer, R. A. (1984). Toward a personal construct conceptualization of depression and suicide. In F. R. Epting \& R. A. Neimeyer (Eds.), Personal Meanings of Death: 
Applications of Personal Construct Theory to Clinical Practice. New York: Hemisphere.

Neimeyer, R. A. \& Feixas, G. (1992). Cognitive assessment in depression: a comparison of some existing measures. European Journal of Psychological Assessment, 8, 47-56.

Noam, G. G., Paget, K., Valiant, G., Borst, S. \& Bartok, J. (1994). Conduct and affective disorders in developmental perspective: a systematic study of adolescent psychopathology. Development and Psychopathology, 6, 519-532. doi:10.1017/S0954579400006088

Oosterwegel, A. \& Oppenheimer, L. (1993). The Self-System. Developmental Changes Between and Within Self-Concepts. Hillsdale, NJ: Erlbaum.

Orth, U., Robins, R. W. \& Roberts, B. W. (2008). Low self-esteem prospectively predicts depression in adolescence and young adulthood. Journal of Personality and Social Psychology, 95(3), 695-708. DOI:10.1037/0022-3514.95.3.695

Papadakis, A., Prince, R., Jones, N. \& Strauman, T. (2006). Self-regulation, rumination, and vulnerability to depression in adolescent girls. Development and Psychopathology, 18, 815-829. Doi:10.1017/S0954579406060408

Pilarska, A. \& Suchańska, A. (2015). Self-Complexity and Self-Concept DifferentiationWhat Have We Been Measuring for the Past 30 Years? Current Psychology, 34(4), 723-743. doi:10.1007/s12144-014-9285-7

Pinquart, M., Silbereisen, R. K. \& Wiesner, M. (2004). Changes in discrepancies between desired and present states of developmental tasks in adolescence: a 4-process model. Journal of Youth and Adolescence, 33, 467-477.

DOI:10.1023/B:JOYO.0000048062.81471.5b 
Salmon, P. (1985). Living in time: a new look at personal development. London: Dent.

Sanz, J. (1992). Constructos personales y sintomatología depresiva: un estudio longitudinal. Revista de Psicología General y Aplicada, 45, 403-411.

Saúl, L. A., López-González, M. Á., Feixas, G., Rubio-Garay, F. \& Domínguez-Simón, M. J. (2014). Conflictos cognitivos en una muestra comunitaria: un estudio exploratorio. Anuario de psicología/The UB Journal of psychology, 44(3), 343-359.

Schwartz, S. J., Klimstra, T. A., Luyckx, K., Hale, W. W., Frijns, T., Oosterwegel, A., ... \& Meeus, W. H. (2010). Daily dynamics of personal identity and self-concept clarity. European Journal of Personality, 25(5), 373-385. DOI: 10.1002/per.798

Schwartz, S. J., Klimstra, T. A., Luyckx, K., Hale III, W. W. \& Meeus, W. H. (2012). Characterizing the self-system over time in adolescence: Internal structure and associations with internalizing symptoms. Journal of Youth and Adolescence, 41(9), 1208-1225. DOI 10.1007/s10964-012-9751-1

Showers, C. J. \& Zeigler-Hill, V. (2003). Organization of self-Knowledge: Features, Functions, and Flexibility. In M. R. Lehary \& J. P. Tangney (Eds). Handbook of Self and Identity (pp. 47-67). New York, London: Guilford Press.

Steiger, A. E., Fend, H. A. \& Allemand, M. (2015). Testing the vulnerability and scar models of self-esteem and depressive symptoms from adolescence to middle adulthood and across generations. Developmental Psychology, 51(2), 236-247. http://dx.doi.org/10.1037/a0038478

Stone, L. B., Hankin, B. L., Gibb, B. E. \& Abela, J. R. (2011). Co-rumination predicts the onset of depressive disorders during adolescence. Journal of Abnormal Psychology, 120(3), 752-757. DOI: 10.1037/a0023384 
Strachan, A. \& Jones, D. (1982). Changes in identification during adolescence: a personal construct theory approach. Journal of Personality Assessment, 46, 529-535. DOI: 10.1207/s15327752jpa4605_15

Walker, B. M. \& Winter, D. A. (2007). The Elaboration of Personal Construct Psychology. Annual Review of Psychology, 58, 453-477. DOI:10.1146/annurev.psych.58.110405.085535

Wang, Y. \& Ollendick, T. H. (2001). A cross-cultural and developmental analysis of selfesteem in Chinese and Western children. Clinical Child and Family Psychology Review, 4, 253-271. DOI: 10.1023/A:1017551215413

Winter, D. A. (1992). Personal Construct Psychology in Clinical Practice. London: Routledge.

Winter, D.A. (2003). Psychological disorder as imbalance. In F. Fransella (ed.), International Handbook of Personal Construct Psychology (pp. 201-210). London: Wiley

Winter, D. A. \& Reed, N. (Eds.). (2016). The Wiley Handbook of Personal Construct Psychology. Chichester, UK: Wiley.

Zentner, M. \& Renaud, O. (2007). Origins of adolescents' ideal self: an intergenerational perspective. Journal of Personality and Social Psychology, 92, 557-574. DOI:10.1037/0022-3514.92.3.557

Zhang, M., Xin, Z. \& Lin, C. (2012). Measures of cognitive complexity and its development in Chinese adolescents. Journal of Constructivist Psychology, 25(2), 91-111. DOI: $10.1080 / 10720537.2012 .651071$ 


\section{Table 1}

Measures of symptoms and measures of self-knowledge organization for the depression and no-symptom samples

\begin{tabular}{lccccc}
\hline \multicolumn{1}{c}{ Measures } & $\begin{array}{c}\text { Depression } \\
\text { M (SD) }\end{array}$ & $\begin{array}{c}\text { No Symptoms } \\
\text { M (SD) }\end{array}$ & F (1,33) & $p$ & $\eta^{2}$ p \\
\hline Symptoms & & & & & \\
$\quad$ CDI & $38.63(4.91)$ & $16.13(1.54)$ & 302.804 & .000 & .903 \\
PSDI & $2.02(.39)$ & $1.35(.15)$ & 41.272 & .000 & .556 \\
S & $.76(.63)$ & $.38(.38)$ & 4.290 & .046 & .115 \\
OC & $1.54(.58)$ & $.91(.41)$ & 13.591 & .001 & .292 \\
SI & $1.79(.73)$ & $.70(.45)$ & 26.686 & .000 & .447 \\
Dp & $1.74(.74)$ & $.38(.29)$ & 47.412 & .000 & .590 \\
A & $1.34(.84)$ & $.50(.42)$ & 13.021 & .001 & .283 \\
H & $1.42(.90)$ & $.69(.43)$ & 8.964 & .005 & .214 \\
PA & $.61(.65)$ & $.18(.29)$ & 6.103 & .019 & .156 \\
IP & $1.48(.75)$ & $.93(.58)$ & 5.891 & .021 & .151 \\
Ps & $1.51(.94)$ & $.43(.38)$ & 18.399 & .000 & .358 \\
Self-organization & & & & & \\
PVFF & $42.01(8.55)$ & $49.72(8.35)$ & 7.233 & .011 & .180 \\
P & $26.01(17.55)$ & $32.35(11.74)$ & 1.517 & .227 & .044 \\
A-I & $0.51(0.25)$ & $0.29(0.28)$ & 6.111 & .019 & .156 \\
A-O & $0.46(0.19)$ & $0.40(0.16)$ & .787 & .382 & .023 \\
I-O & $0.40(0.14)$ & $0.37(0.13)$ & .548 & .464 & .016 \\
N cases with ID & $14(73.68)$ & $4(25)$ & $\chi^{2}(1, N=35)=8.241$ & .004 & $\varphi=-.485$ \\
(\%) & & & & & \\
\hline & & & & & \\
\end{tabular}

M: Mean; SD: Standard deviation; CDI: Children Depression Inventory; DI; PSDI: Positive Symptoms Distress Index (BSI); S: Somatization; OC: Obsession-Compulsion; SI: Interpersonal Sensitivity; Dp: Depression; A: Anxiety; H: Hostility; PA: Phobic Anxiety; Paranoid Ideation (PI); Ps: Psychoticism. PVFF: Percentage of Variance accounted for by the First Factor; P: Polarization; ID: Presence of Implicative Dilemmas; A-I: Discrepancy between Actual and Ideal Selves; A-O: Discrepancy between Actual Self and Others; I-O: Discrepancy between Ideal Self and Others. 
Table 2

Correlations (Pearson) between self-knowledge organization measures and severity of symptoms, by sample (Depressive and No symptoms)

\begin{tabular}{|c|c|c|c|c|c|c|c|c|c|c|c|c|}
\hline & \multicolumn{6}{|c|}{ Depressive } & \multicolumn{6}{|c|}{ No symptoms } \\
\hline & PVFF & $\mathrm{P}$ & A-I & $\mathrm{A}-\mathrm{O}$ & $\mathrm{I}-\mathrm{O}$ & ID & PVFF & $\mathrm{P}$ & A-I & $\mathrm{A}-\mathrm{O}$ & $\mathrm{I}-\mathrm{O}$ & ID \\
\hline CDI & .061 & .25 & .297 & $.484^{*}$ & .209 & .129 & $-.731 * *$ & .123 & -.082 & .257 & .149 & -.241 \\
\hline PSDI & -.268 & .328 & .321 & $.545^{*}$ & .396 & .357 & $-.608 *$ & .138 & .052 & .109 & -.086 & .215 \\
\hline $\mathrm{S}$ & .022 & .423 & $.477 *$ & .392 & .225 & .044 & .163 & -.319 & .362 & .116 & -.323 & .070 \\
\hline $\mathrm{OC}$ & -.150 & .160 & $.564 *$ & .274 & .176 & $.542^{*}$ & -.195 & .118 & .186 & .130 & -.098 & .075 \\
\hline IS & -.205 & .330 & .392 & $.548^{*}$ & .322 & .423 & .202 & -.159 & -.176 & -.151 & -.429 & -.270 \\
\hline $\mathrm{Dp}$ & -.078 & .455 & .372 & $.662 * *$ & .197 & .250 & .122 & -.019 & .292 & .138 & -.260 & .172 \\
\hline A & -.037 & .433 & $.468 *$ & $.571 *$ & .291 & .294 & .217 & -.215 & .356 & .137 & -.288 & -.119 \\
\hline $\mathrm{H}$ & $-.515^{*}$ & .014 & .358 & .075 & .084 & .310 & .247 & .005 & .386 & .202 & -.063 & -.190 \\
\hline PA & -.167 & .167 & .190 & .356 & .042 & .349 & .149 & -.218 & -.216 & -.279 & -.331 & -.256 \\
\hline PI & -.329 & .042 & .384 & .254 & .044 & $.462 *$ & .035 & -.179 & -.080 & -.285 & -.459 & .281 \\
\hline Ps & -.077 & .377 & .259 & $.677 * *$ & .229 & 199 & .174 & -.072 & -.231 & -.200 & -.408 & .039 \\
\hline
\end{tabular}

M: Mean; SD: Standard deviation; CDI: Children Depression Inventory; DI; PSDI: Positive Symptoms Distress Index (BSI); S: Somatization; OC: Obsession-Compulsion; SI: Interpersonal Sensitivity; Dp: Depression; A: Anxiety; H: Hostility; PA: Phobic Anxiety; Paranoid Ideation (PI); Ps: Psychoticism. PVFF: Percentage of Variance accounted for by the First Factor; P: Polarization; ID: Presence of Implicative Dilemmas; A-I: Discrepancy between Actual and Ideal Selves; A-O: Discrepancy between Actual Self and Others; I-O: Discrepancy between Ideal Self and Others.

* Correlation is significant at the 0.05 level (2-tailed).

** Correlation is significant at the 0.01 level (2-tailed). 
Figure 1. Illustration of the basic structure of an implicative dilemma found in the repertory grid of a participant in the Depressive sample.

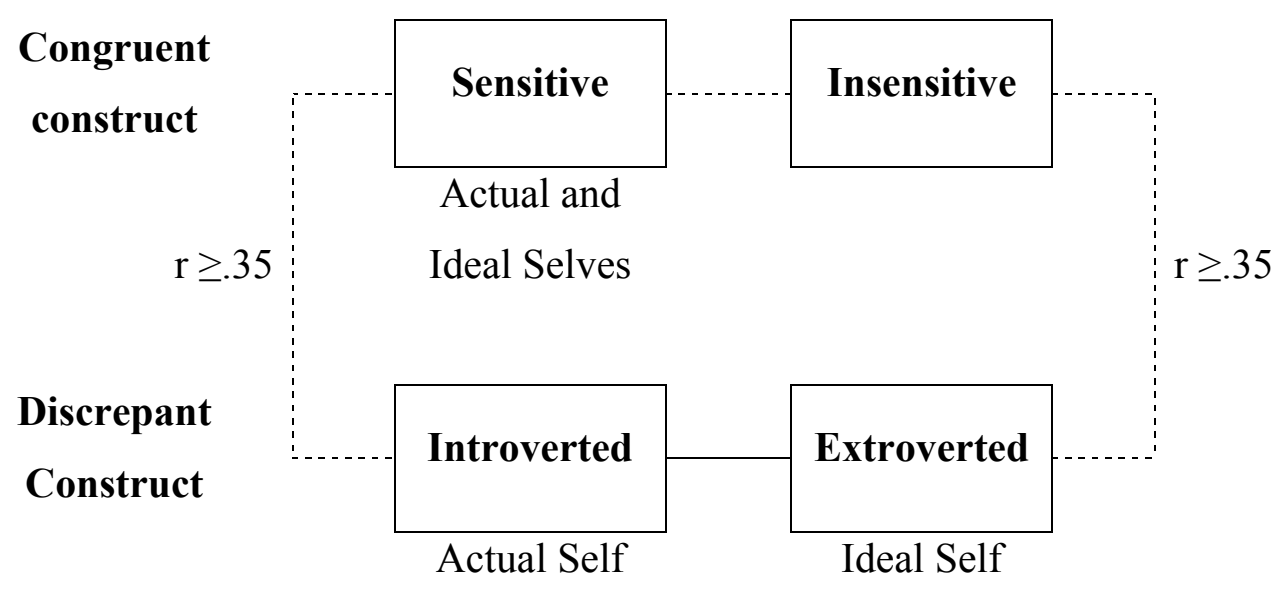

